\title{
A Case of Gastroduodenal Strongyloidiasis Causing Protein Losing Enteropathy
}

\author{
Sandheep Janardhanan, Benoy Sebastian, Mary George, Sunil Mathai, Ashfaq Ahmed, Saji John \\ Varghese \\ Department of Gastroenterology, Medical Trust Hospital, Cochin, Kerela, India
}

\begin{abstract}
Strongylodiasis is an intestinal parasitic infection which can cause cataclysmic hyper infection syndrome in immunocompromised. Here we report an interesting and rare case of gastroduodenal strongyloidiasis presenting as protein losing enteropathy which was promptly diagnosed and dramatically reversed with antihelminthic therapy. $J$ Microbiol Infect Dis 2020; 10(4): 237-239.
\end{abstract}

Keywords: Strongyloidiasis, protein losing enteropathy, hyperinfection

\section{INTRODUCTION}

Strongyloide stercoralis is an intestinal nematode with a complicated life cycle that involves gastrointestinal and respiratory systems. It affects millions worldwide, with predilection for tropical areas. In healthy it is mostly subclinical, however in elderly and immune compromised it can be catastrophic. Here we report an interesting and rare case of gastroduodenal strongyloidiasis presenting as protein losing enteropathy in an elderly immunocompromised patient.

\section{CASE REPORT}

A seventy-year-old gentleman was admitted in in orthopedic department with complaints of progressive hip pain and became moribund in the last few weeks. He was diagnosed to have osteoarthritis and advised hip replacement. He had significant comorbidities like Rheumatoid arthritis (10 years on disease-modifying antirheumatic drugs and Non-steroid antiinflammatory drugs on and off, irregular followup) and Type 2 Diabetes mellitus (20 years, on insulin and oral hypoglycemic drugs). Apart from his complaint, he also had progressive bilateral lower limb swelling and on and off loose watery stools for past three months, baseline evaluation revealed hypo albuminemia and gastroenterology opinion was sought. On examination he was emaciated (Body Mass Index 18.4), Triceps skin fold thickness $(10 \mathrm{~mm}$,
$\mathrm{N}-15$ to 20 ). He had pallor and bilateral pitting pedal edema. Systemic examination was within normal limit apart from free fluid in abdomen and he had no markers of liver cell failure.

Baseline investigations revealed anemia $(\mathrm{Hb}-8$, normocytic normochromic picture with mild eosinophilia), and severe hypoproteinemia (4.7 $\mathrm{mg} / \mathrm{dl})$, hypoalbuminemia $(1.8 \mathrm{mg} / \mathrm{dl})$ and hypoglobulinemia $(2.9 \mathrm{mg} / \mathrm{dl})$. Stool examination was within normal limit and didn't reveal any abnormal findings. After considering and doing relevant investigations and imaging ruling out other causes of hypoproteinemia and pedal edema (chronic liver disease, diabetic nephropathy/renal failure, chronic pancreatitis, congestive cardiac failure, paraprotenemia, hypothyroidism etc.). Provisional diagnosis of protein losing enteropathy was made and we proceeded with pan endoscopy. Esophagogastroduodenoscopy showed edematous gastric and duodenal folds and no evidence of any varices or portal gastropathy while colonoscopy was normal. Segmental biopsies were taken and were reported as gastric and duodenal strongyloidiasis. Both larval and adult forms were detected and associated eosinophilic invasion and abscess seen. Now with the diagnosis made, we commenced him on tablet Ivermectin $12 \mathrm{mg}$ (two repeated doses, one week apart)

One month on follow-up visit, his improvement was stark, His pedal edema vanished, loose 
stools resolved, serum albumin doubled (3.5 $\mathrm{mg} / \mathrm{dl})$, anemia improved ( $\mathrm{Hb} 11.5 \mathrm{~g} / \mathrm{dL})$, and he gained a stone (around $6 \mathrm{~kg}$ ) in weight. His clinical improvement was corroborated with repeated upper endoscopy which documented histological elimination of parasitosis.
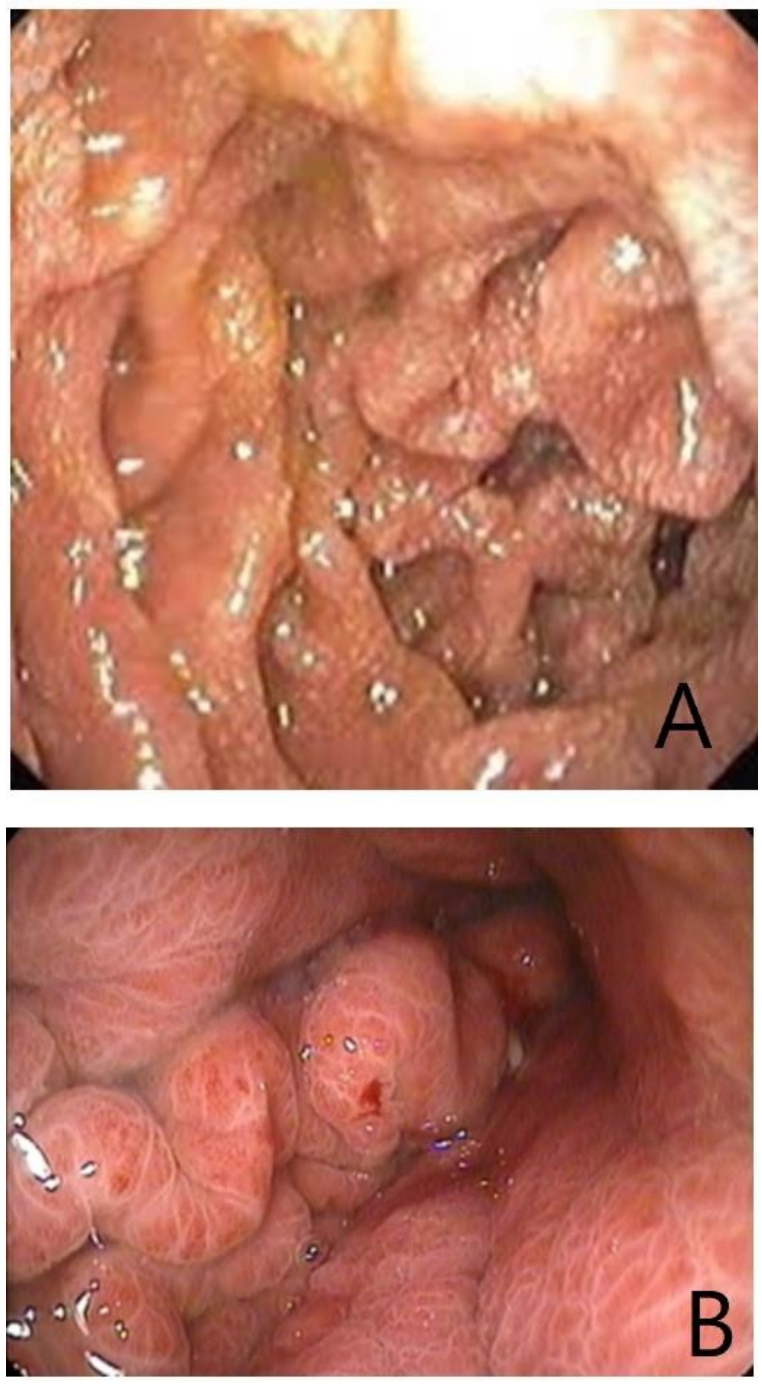

Figure 1 A \& B. Upper gastrointestinal visualization showed erythematous gastric and duodenal folds.

Both low and high-power views of duodenal mucosa showed moderate to severe eosinophilia. In fact, the high-density pf eosinophils caused formation of eosinophilic abscess in duodenum. Also, both the larval and adult forms of Strongyloides were seen abundantly in duodenal mucosa. Interestingly, stomach mucosa, where parasitosis is very uncommon because of hostile $\mathrm{pH}$, was teeming with both adult and larval forms of Strongyloides. Apart from these, there was no evidence of malignancy/granuloma or other abnormal findings.

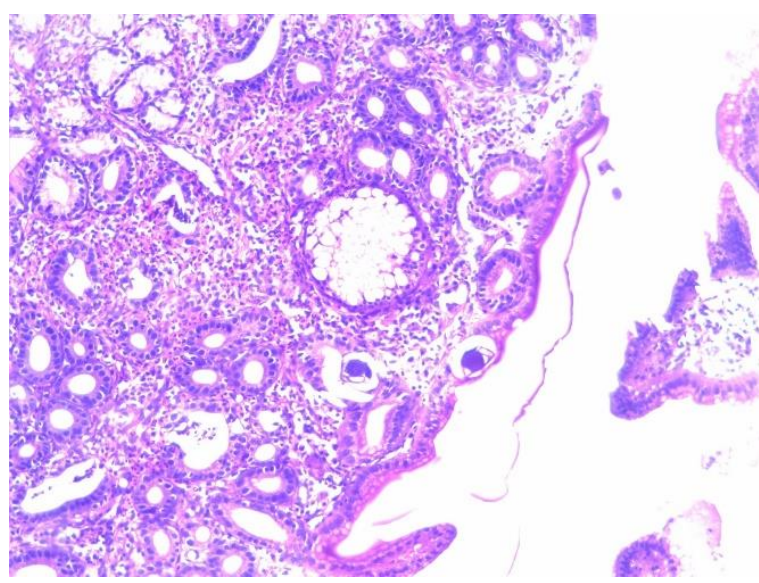

Figure 2. Low power view of duodenal mucosa showing larval and adult forms.

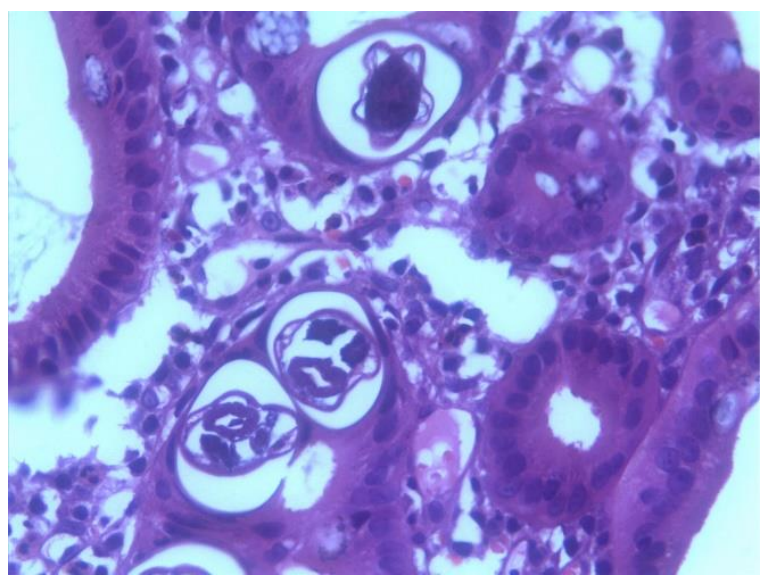

Figure 3-High power view of stomach mucosa showing larval and adult form of parasite.

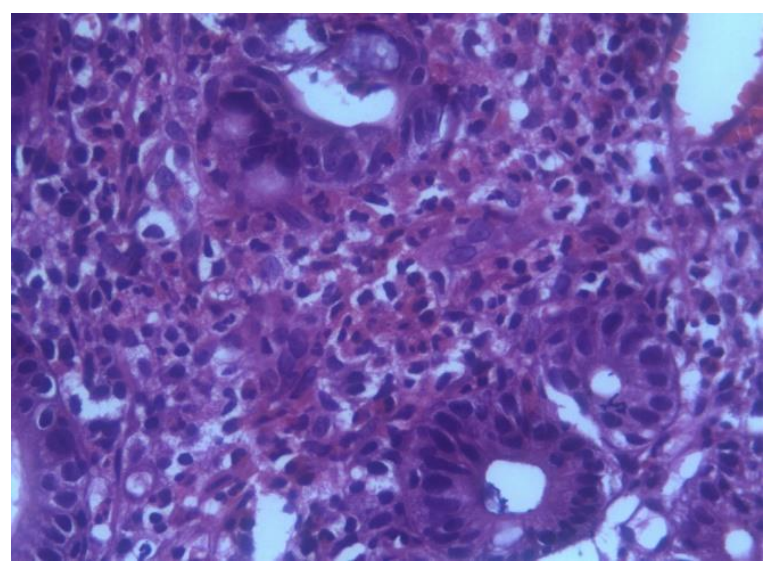

Figure 4. High power view of duodenal mucosa showing eosinophilia and eosinophilic abscess.

\section{DISCUSSION}

Strongyloidiasis is a parasitic nematode that affects 50 to 100 million worldwide. In 
immunocompromised the seemingly innocuous cause visceral larval dissemination leading to cataclysmic Strongyloides hyperinfection syndrome which left untreated can cause mortality around $50-70 \%$ [1].

In our patient hyper infection syndrome was manifested in gastrointestinal tract as protein losing enteropathy causing pedal edema, hypoalbuminemia and diarrhea. Peripheral eosinophilia is a strong indicator of strongyloidiasis but lacks specificity. Similarly, a single stool sample has only $30 \%$ sensitivity and even after multiple sampling, it is around 70 \%only. ELISA can also be used but doesn't differentiate current and past infection [2].

Endoscopic findings are nonspecific and may reveal erythema and edema of mucosa, and sometimes there will not be any morphological abnormalities and has to hence the need for biopsy and histology [4, 5].

Another unique fact is that our patient had gastric strongyloidiasis. Normally, the stomach is hostile to parasites because of presence of gastric acid, but in chronic infections and concomitant proton pump usage, the scenario is compromised. In some cases, it can even cause torrential bleeding and even gastric outlet obstruction [6-8].

Uncomplicated cases can be treated with Ivermectin $250 \mathrm{mcg} / \mathrm{kg}$ single dose, whereas in case of hyper infection like our case, it may be necessary to repeat the dose. Albendazole, mebendazole and thiabendazole are second line treatment options [9]. Unfortunately, in a tropical country like ours such infections can be easily missed unless analyzed with an eagle's eye [10, $11]$.

This is a case of Strongyloides hyperinfection syndrome in an elderly immunocompromised patient. The parasitosis manifested as gastroduodenitis causing protein losing enteropathy and was promptly diagnosed and dramatically reversed with anthelmintic therapy. Added to the fact that gastric strongyloidiasis is rare makes this case unique, and to our best our knowledge first such case report from our part of the country.

\section{ACKNOWLEDGMENTS}

Statement of Ethics: Consent of the patient obtained. Ethical clearance not obtained since the patient's detail was not divulged.

Conflict of interest: The authors declare no personal or financial conflict of interest.

Financial Disclosure: No financial support was received.

\section{REFERENCES}

1. Zaghlool DA, Hassan AA, Moustafa AM, Shahin WA. A case of fatal gastrointestinal hemorrhage due to hyper infection with Strongyloides stercoralis $\mathrm{J}$ Parasit Dis 2016; 40(4): 1347-1350.

2. Buonfrate D, Requena-Mendez A, Angheben A, et al. Severe strongyloidiasis: A systematic review of case reports. BMC Infect Dis 2013; 13:78.

3. Schär F, Trostdorf U, Giardina F, et al. Strongyloides stercoralis: Global distribution and risk factors. PLoS Negl Trop Dis 2013; 7:e2288.

4. Sebastian Anitha, Muttath Radhika, Madhavan Indira, Thomas Vinu. A case of Strongyloides hyperinfection syndrome. Trop $\mathrm{J}$ Med Res 2014;17(2):140-142.

5. Agrawal V, Agarwal T, Ghoshal UC. Intestinal strongyloidiasis: a diagnosis frequently missed in the tropics. Trans R Soc Trop Med Hyg 2009; 103:242-246.

6. Adedayo O, Grell G, Bellot P. Hyperinfective strongyloidiasis in the medical ward. South Med $\mathrm{J}$ 2002; 95:711-716.

7. Yaldiz M, Hakverdi S, Aslan A, Temiz M, Culha G. Gastric infection by Strongyloides stercoralis: a case report. Turk J Gastroenterology 2009; 20(1):48-51.

8. Ebrahimpour S, Sadeghi-Haddad-Zavareh $M$, Ahangar ZD, et al. Unusual form of strongyloidiasis with gastric involvements: A case report. J Acute Diseases 2019; 8(3):127-129.

9. Henriquez-Camacho C, Gotuzzo E, Echevarria J, et al. Ivermectin versus albendazole or thiabendazole for Strongyloides stercoralis infection. Cochrane Database Syst Rev 2016; 18(1): CD007745.

10. Gupta V, Bhatia S, Mridha AR, Das P, Khanna N. Strongyloides stercoralis hyperinfection: An often missed but potentially fatal cause of anemia and hypoalbuminemia in leprosy patients on long-term steroid therapy. Indian J Dermatol Venereol Leprol 2017; 83(3): 381-383.

11. Rivasi F, Pampiglione S, Boldorini R, Cardinale L. Histopathology of Gastric and Duodenal Strongyloides stercoralis Locations in Fifteen Immunocompromised Subjects. Archiv Pathology Labor Med 2006; 130(12): 1792-1798. 